\title{
HEALTH SERVICE PROVISION FOR MEDICAL EDUCATION IN ENGLAND AND WALES: CAN STANDARDS BE MAINTAINED?
}

Under the above title a one-day Conference was recently held under the auspices of three relatively new organizations: The University Hospitals Association; the Medical Academic Staff Committee of the BMA; and the Federation of Associations of Clinical Professors. The existence of these bodies themselves reflects the growing recognition that academic medicine does not have a strong enough voice in the world of medical politics, especially as regards the allocation of resources. The meeting was attended by Sir Henry Yellowlees and at the beginning also by $\mathrm{Dr}$ Gerard Vaughan. We should note with pleasure that we are the only Medical College with a Fellow who is a Minister in the Government.

Professor Gerald Russell and I were the only psychiatrists there, so it seems advisable for a short report of this important meeting to be made more generally available. There was a wide-ranging discussion that revealed several broad areas of disagreement with virtual unanimity only on the fact that there was not enough money and no more coming, so that some of the issues could be boiled down to 'bread for all or cake for some'. It was also made clear that, if there was no cake now, then the bread of the future would be of inferior quality. Much of the discussion was inconclusive because we were all waiting for Merrison in the hope that his report would form a good basis for action as well as discussion. Many of the discussion points could be classified in the following ways:

1. The issues of teaching versus non-teaching hospitals, with special reference to SIFT; that is, special increment for teaching. It was generally agreed that this formula does not properly represent the increased cost of the health services required for teaching purposes, though one speaker did wonder why even academic meals seemed to cost more than non-academic ones. The important point in this connection was a general feeling that in the planning and allocation of services, the University voice was heard too little and too late at all planning levels, whether Regional, Area or District. Most important of all, at the top level, academic medical opinion did not have a clear path to the Department and Sir Henry Yellowlees himself thought there might be a case for another committee. Others felt that strengthening the Joint Consultants Committee as regards the University component would be better than a parallel channel of advice.

2. There were obvious tensions between London and the Rest, with special reference to the shortcomings of RAWP (the Resource Allocation Working Party). Many feel this seems to be just a device for preventing the maintenance of essential services in London (no question of improving them) without there being much visible increase in the resources in the provinces. It would appear that the cost per head of educating medical students in the new schools is less than in London, but some did wonder whether that would last much longer when the new schools build up their research and teaching staff.

3. The question of undergraduate versus postgraduate teaching hospitals was to a certain extent mixed up with the second point, as it is in London that the postgraduate schools are so large and important. Centres of excellence only eat cake, and trainees aspiring to research or a high level in specialized clinical work want to work at the best centres and not be spread equitably round the country for service reasons.

4. The discussion was mainly on the central subjects of medicine and surgery, and comparatively little was said about the different needs of different parts of medicine, though at one stage the difficulties of recruitment and training for mental handicap received a good deal of discussion. Professor Russell made the point that creating Chairs does not necessarily promote recruitment into unpopular specialties. General social attitudes expressed directly and indirectly (through, for example, public Inquiries) create such a bad image that special incentives are perhaps necessary if people of adequate quality are to be attracted, even though there is a danger that some people might be only in them for the money.

In some ways it was a disappointing day with defensive reactions around entrenched positions occupying most of the time. There was a general desire to do the same old thing only more cheaply, and really only lipservice was paid to academic teaching moving into the community and being more concerned with preven- 
tion. Perhaps a change of Government may symbolize a change of social attitude and more experimentation will be allowed in different Regions. Instead of concentrating on producing more doctors more cheaply, it might be better for medical schools to experiment with other forms of delivery of health care, with greater use of nurses and other non-medical personnel. Why should we not find this as effective as other under-developed countries do?

Desmond Pond

\title{
TRAINING IN PSYCHOTHERAPY THE ABERDEEN UNIVERSITY DIPLOMA COURSE: SECOND REPORT
}

\author{
By J. D. Haldane; D. A. Alexander; J. G. Hebditch and L. G. Walker \\ Department of Mental Health, University of Aberdeen
}

Our intention in this paper is to describe recent developments in the aims, content and organization of a psychotherapy course which began in 1965 (Millar et al 1968) and the factors which have influenced these developments.

\section{Local Factors}

In the Aberdeen area, a professional environment supportive to the practice of and training in psychotherapy helped in setting up, sustaining and developing the Diploma in Psychotherapy Course. Between 1965 and 1978, either the one year full-time or the two year part-time course was successfully completed by 31 candidates; 25 psychiatrists, 4 clinical psychologists, one educational psychologist and one psychiatric nurse. In 1976, a trained psychoanalyst was appointed to a new post of Consultant Psychiatrist with a special responsibility for psychotherapy. It would be unrealistic to expect that all professional staff in this area should approve or support to an equal degree, the development of psychotherapeutic practice or training. It can, however, be claimed that in the case of those who wish to have training in psychotherapy or to develop existent skills, experienced colleagues are ready to assist them.

In this Health Board Area, throughout the three year period of preparation for the College's Membership examination, all psychiatrists-in-training are offered didactic teaching and supervised clinical experience in psychotherapy. Consultation, supervision and training in, psychotherapy with children, adolescents, adults, 'couples, families and groups are undertaken by suitably qualified staff from University and NHS departments. Other staff, e.g. psychologists, social workers, nurses, from NHS and local authority departments, also make use of these resources.
Topics of relevance to psychotherapy have been the subject of two open departmental lectures for each of the past two academic sessions. In addition, during the academic session 1979-80 there will be the first of a series of annual lectures on psychotherapy to be called the Malcolm Millar Lectures, which have been made possible by a donation to the University.

Since early 1978 a local branch of the Association for Family Therapy has had a regular monthly programme of evening, whole day and residential meetings, with both local and external staff contributing to the programme.

\section{Other Factors}

In recent reviews of the Diploma Course, and planning for its development with our supervisor colleagues, we have tried to take into account factors in addition to those particularly relevant to the local situation.

The practice of psychotherapy has never been exclusive to the medical profession, far less to psychiatrists. Local experience confirms what are widespread trends: that professional workers other than psychiatrists also seek appropriate supervision and training; and that colleagues from different disciplines and professions benefit from sharing teaching, supervision and training.

There is a continuing debate between those who see the only acceptable training for psychotherapy as being within the psychoanalytic model, including the experience of a personal analysis, e.g. Sutherland $(1968,1976)$, and those who consider that there are other appropriate schemes of training and preparation, e.g. Marks (1971). We note with interest that this important issue has received very little attention in the Journal or Bulletin of the Royal College of Psychiatrists. For whatever other reasons this debate may be of 